\title{
SOUTHWARD MIGRATION OF SWAINSON'S HAWKS: OVER 10,000 KM IN 54 DAYS
}

JOSEF K. SCHMUTZ, Department of Biology, University of Saskatchewan, 112 Science Place, Saskatoon, SK. S7N 5E2, C. STUART HOUSTON, 863 University Drive, Saskatoon, SK. S7N 0J8, and GEOFFREY L. HOLROYD, Canadian Wildlife Service, 499998 Avenue, Edmonton, AB. T6B 2X3

Swainson's Hawks that breed in Saskatchewan and Alberta travel more than $10,000 \mathrm{~km}$ to spend the austral summer in what we call (erroneously) their "wintering grounds." Taking advantage of north winds and using thermals to soar with minimal energy expenditure, they migrate south in flocks of many thousands and appear to go long distances without food, as lack of feces or wash below their night roosts suggests that they haven't eaten in some time. ${ }^{6}$ In 1972 Neal Smith counted 344,409 Swainson's Hawks passing over Ancon Hill near Panama City in fall migration. ${ }^{5}$ Some hawks arrive on the pampas of Argentina so weak that they have been picked up by hand. ${ }^{3}$ This paper describes the timing and route of autumn migration of Swainson's Hawks as determined from selected band recoveries and by satellite radio transmitters.

The migration route and "wintering" grounds are known from banding: 547 recoveries of 538 Swainson's Hawks from 14,784 banded throughout North America since 1923. Each recovery results only when someone, by chance, happens to find a leg band on a dead or injured hawk. A relatively small number of these recoveries offer exact dates of death, such as a bird killed on the highway or shot, to provide precise information on the timing of their southward progress.
Twenty-four recoveries met these criteria: 18 hawks recovered in their hatching year $(H Y)$ and 6 recovered in subsequent years (AD) (Figure 1). From Guatemala the earliest band recovery was 7 October, from Colombia 22 October, and from Argentina 15 November. A late hawk was still in Texas when shot on 30 November. Some hawks migrate about a month later than others. However, all of the late birds are young of the year. Although the sample size for adults is small, no adults were reported late on the autumn migration. The migration was calculated as roughly two months in duration.

The average compass direction of travel followed to Argentina is nearly southeast $\left(140^{\circ}\right)$. This direction averages $15^{\circ}$ more southerly than the average for smaller birds such as the Tree Swallow. ${ }^{7}$ In terms of longitude, all Swainson's Hawk recoveries in the United States were between $96^{\circ}$ $\mathrm{W}$ and $105^{\circ} \mathrm{W}$, a migration pathway that appears especially narrow in Oklahoma and Texas.

Swainson's Hawks were once subject to considerable pressure from shooting; 60 of the 81 recoveries $(74.1 \%)$ from hawks banded before 1954 were shot. ${ }^{4}$ Of birds banded since 1955 only 19 of 362 (5.2\%) hawks recovered in Canada or the United States had been shot, whereas 44 of $96(45.8 \%)$ of those 


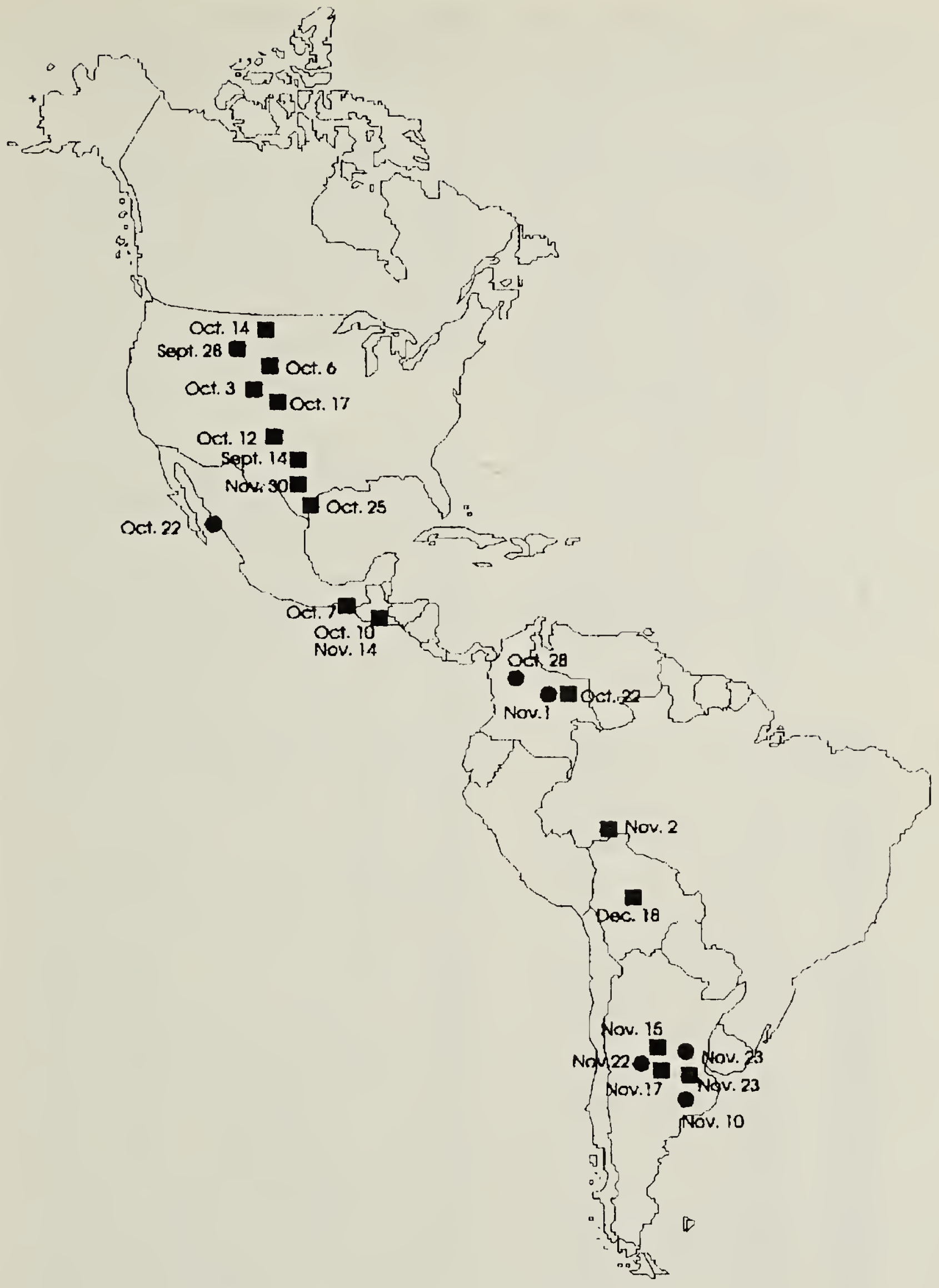

- $\mathrm{AD}$

a $H Y$

Figure 1. Locations and dates of 24 autumn band recoveries of Swainson's Hawks. Squares are hawks banded as nestlings and recovered in their hatching year (HY). Circles are hawks recovered after their first year; only the 22 October sighting in Mexico and the 1 November shooting in Argentina were banded as adults (AD). 


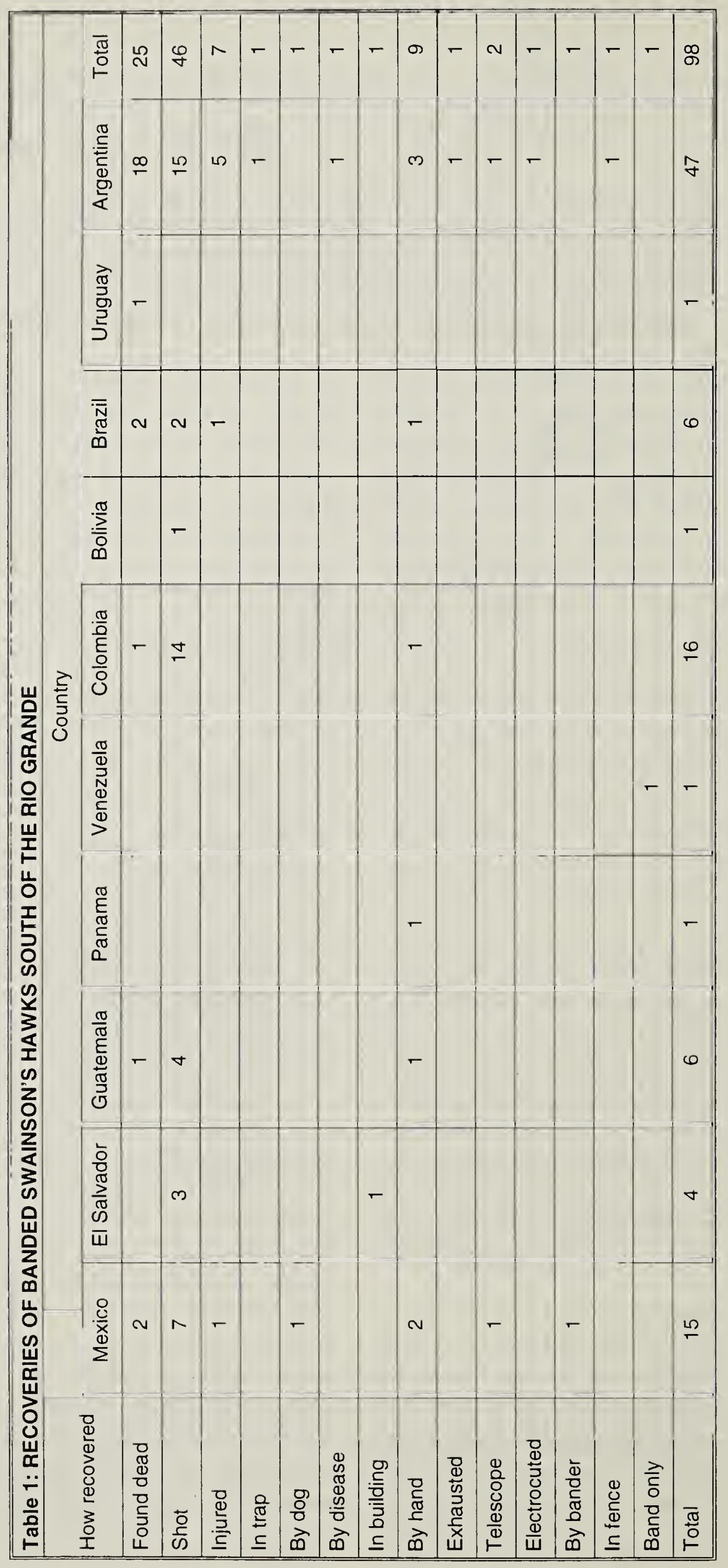


recovered in Central and South America had been shot. In Colombia 14 of 16 had been shot (Table 1).

However, band recoveries fail to provide information about the speed of migration of any individual hawk. Even when we know the exact date a bird died in Colombia or Argentina, we do not know when that bird left its territory in Saskatchewan or Alberta or how often it stopped.

Conventional radiowave telemetry has been used for 30 years in local areas to study territory size in hawks; two receivers are used to locate an animal through triangulation. More recently, powerful radios send microwaves to satellites in near space, approximately $800 \mathrm{~km}$ above the earth (satellite radiotelemetry). ${ }^{1}$ A single satellite passing overhead has the capacity to calculate a hawk's location using the doppler effect, similar to the sound of a passing train. Transmitters are now small enough $(28 \mathrm{~g})$ to allow satellite telemetry of Swainson's Hawks. In 1994, Brian Woodbridge, of the United States Forest Service, used a satellite transmitter to track a female Swainson's Hawk from its nest in northern California to Argentina. Transmissions were received by National Oceanic and Atmospheric Administration weather satellites in polar orbit and relayed to a data processing centre in Maryland. In Argentina the sequential transmitter locations led Woodbridge to loose flocks of as many as 4,000 hawks and to observe over 700 hawks that had died from pesticide poisoning. ${ }^{8}$

In 1995, the radiotelemetry effort was extended. Twelve adult Swainson's Hawks were trapped at their nests and fitted with radio transmitters attached by backpack harness; nine functional transmitters were from California (1), Utah (1), Colorado (2), Idaho (3), and Alberta (2). In Alberta, the transmitters were attached to an adult male and an adult female near Hanna by Ursula Banasch and Kort Clayton on $24 \mathrm{Au}$ gust 1995 . To conserve battery strength, the radios are programmed to give signals only every third or seventh day. The location at a particular moment is most exact when the signal is of high quality, specified as two satellite fixes within 0.1 degree of latitude and longitude, or within about $6 \mathrm{~km}$ of each other; such a result is rated as a class 1 or 2 signal. When a lesser signal (termed Class A or B) is received, it provides a less reliable location "fix" and should be treated with considerable caution.

The two radio-equipped hawks provided, for the first time, the rate of southward travel of two Swainson's Hawks from the Canadian prairies (Figure 2). Both hawks were near their nests in Alberta on 14 September. By 23 September both sent radio signals from southwestern Saskatchewan. Both travelled across the US mid-west in early October to the Caribbean coast of northern Mexico, across Mexico to the Pacific coast state of Oaxaca, and through Central America in mid-October. They reached Colombia by the end of October, crossed the Andes and migrated down the east side of these mountains, through western Brazil, and arrived in Argentina by 7 November. Once in Argentina they drifted farther south, between 7 November and 3 December, the female travelling a further $650 \mathrm{~km}$ on a course slightly east of south.

The adult female, with twiceweekly radio transmissions via satellite, made the long journey in 53 days and the adult male, with radio 


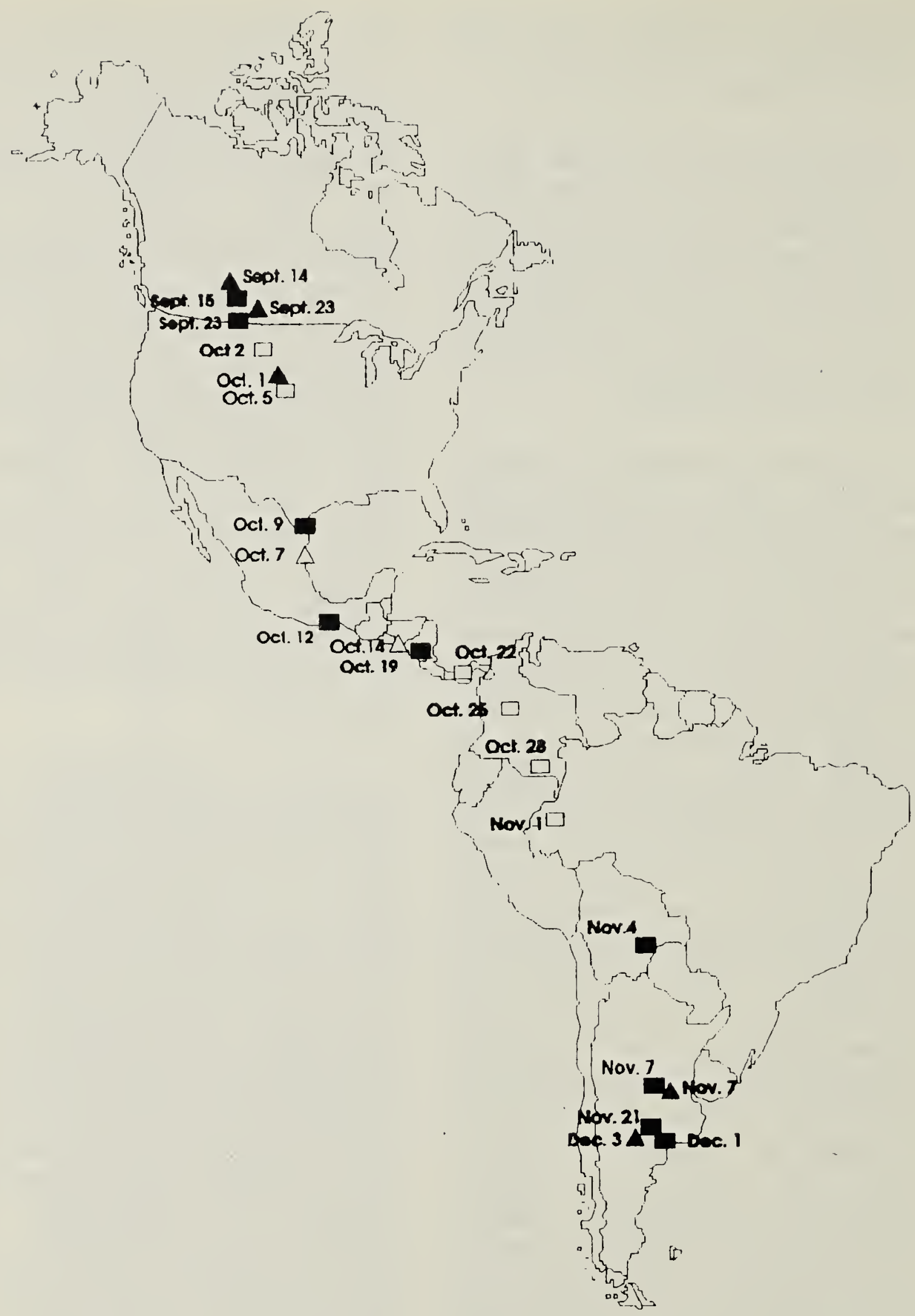

remole

$\Delta$ mats

Figure 2. Locations and dates of two Swainson's Hawks that carried satellite transmitters from southern Alberta in 1995. Square is the female, triangle is the male. Open squares and triangles indicate less accurate class $A$ and $B$ signals. 


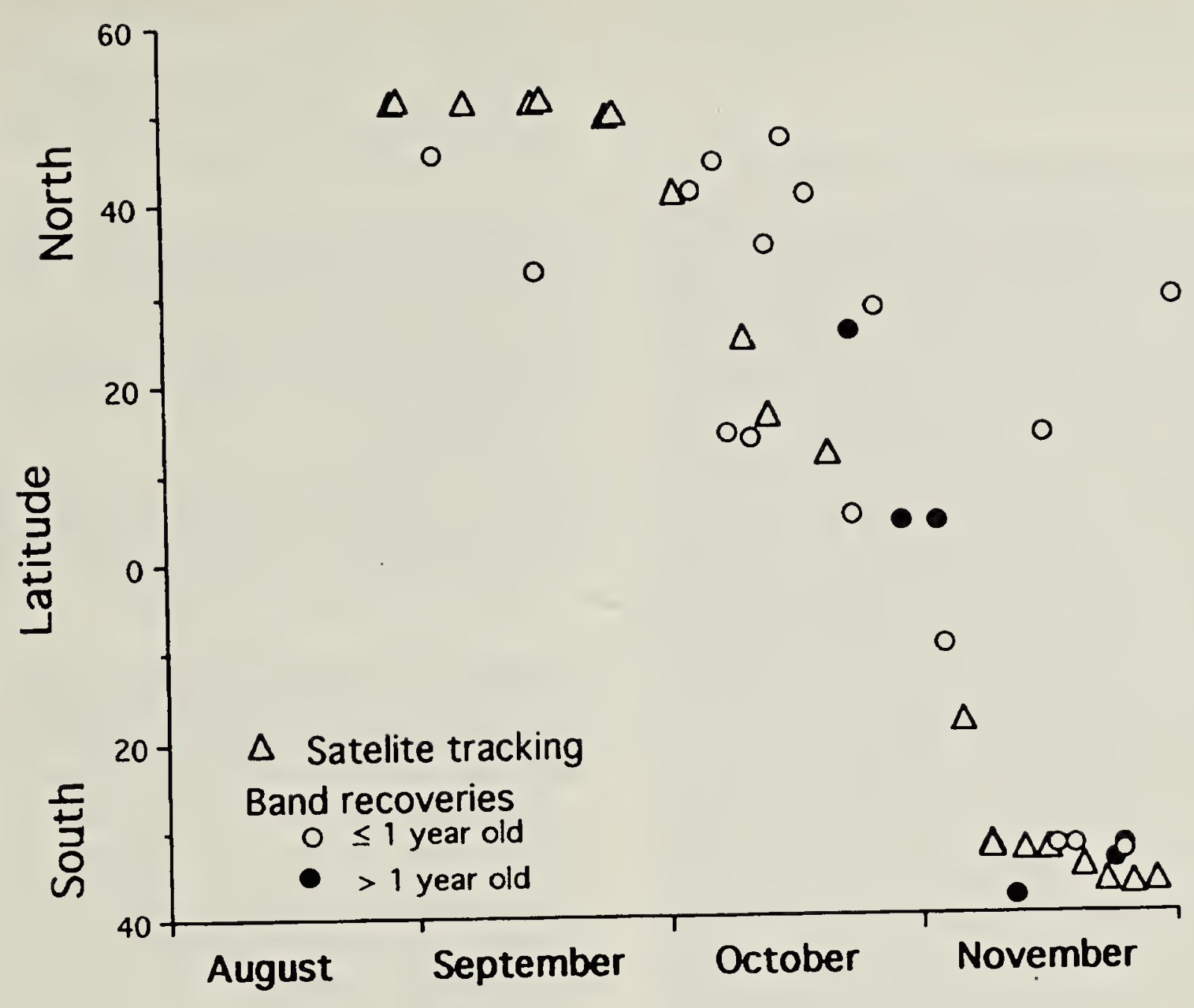

Figure 3. Latitudinal progress of southward migration until the end of November. Triangles represent satellite radio tracking; open circles represent banded hawks recovered in their hatching year; closed circles represent recoveries of older hawks.

fixes given weekly, in about 54 days. The overall average distance travelled by the female was $198 \mathrm{~km}$ per day (range $29-565 \mathrm{~km} /$ day), and for the male $194 \mathrm{~km}$ per day (range 43$362 \mathrm{~km} /$ day). All figures are approximate since a hawk may have left a day or two later and/or arrived a day or two earlier than our records show. Over a seven-day period in early October and two three-day periods in early November, during migration, the female averaged 536, 565, and $473 \mathrm{~km} /$ day, respectively. The male covered $362 \mathrm{~km} /$ day between $\mathrm{Ne}$ braska and the southern border of Tamaulipas, Mexico. Neither hawk appeared to have made any prolonged stops to feed. Although we have gained more precise information on the timing of migration than from 70 years of band recoveries, the results for the two radioequipped adults, plotting date against latitude, correspond quite closely with the results of band recoveries (Figure 3).

The combined results of the two techniques also have provided an unanticipated by-product - they raise two conservation concerns. The first is the high proportion of hawks that are still being shot, especially in Central and South America. Second, the presence of transmitter birds caused Brian Woodbridge to follow his radio hawk in Argentina and thereby happen on 700 dead Swainson's Hawks, including one banded in southwest Saskatchewan, that were killed by pesticide spraying in Argentina. ${ }^{8}$ In January and early February 1996, Marc Bechard, Brian Woodbridge and Mike Goldstein took turns visiting the sites of radio birds in Argentina, and the latter two happened on massive kills. From 4,847 
carcasses, nine carried bands, six of which had been placed in Saskatchewan and Alberta.

Acknowledgements We thank Ursula Banasch and Kort Clayton for trapping the hawks and attaching the radios. Ursula and an anonymous reviewer also provided constructive criticism. We thank Colleen Hyslop, Loney Dickson and Dorothy Kessler of Canadian Wildlife Service for assistance in acquiring the two transmitters; Brian Woodbridge, USDA Forest Service, for the signal locations; and Mark Fuller, US National Biological Survey, for the necessary paperwork to obtain approval for use of the transmitters. Funding was provided by the Canadian Wildlife Service's Latin American program and USDA Forest Service. Ann Demers of the Bird Banding Office, Canadian Wildlife Service, supplied the printout and disk of all North American Swainson's Hawk recoveries through 1992.

1. FULLER, M.R., W.S. SEEGAR, J.M. MARZLUFF, and B.A. HOOVER. 1995. Raptors, technological tools and conservation. Pp. 131-144 in
Transactions of the Sixtieth North American Wildlife and Natural Resources Conference, Minneapolis, Minnesota (Wadsworth, K.G. and R.E. McCabe, eds.). Wildlife Management Institute, Washington, D.C.

2. HOUSTON, C.S. 1968. Recoveries of Swainson's Hawks banded in Saskatchewan. Blue Jay 26:86-87.

3. HOUSTON, C.S. 1990. Saskatchewan Swainson's Hawks. Am. Birds 44:215-220.

4. HOUSTON, C.S. and J.K. SCHMUTZ. 1995. Swainson's Hawk banding in North America to 1992. North American Bird Bander 20:120-127.

5. SMITH, N.G. 1985. Counting migrating raptors. Pp. 239-242 in Proceedings of hawk migration conference IV (Harwood, M., ed.). Hawk Migration Association of North America.

6. SMITH, N.G., D.L. GOLDSTEIN, and G.A. BARTHOLOMEW. 1986. Is longdistance migration possible for soaring hawks using only stored fat? Auk 103:607-611.

7. STILES, D.J. and M.I. HOUSTON. 1994. Distant travels of Tree Swallows of the prairie provinces. Blue Jay 52:206-212.

8. WOODBRIDGE, B., K.K. FINLEY and S.T. SEAGER. 1995. An investigation of the Swainson's Hawk in Argentina. J. Raptor Res. 29:202-204.

The most wonderful mystery of life may well be the means by which it created so much diversity from so little physical matter. The biosphere, all organisms combined, makes up only about one part in ten billion of the earth's mass. It is sparsely distributed through a kilometer-thick layer of soil, water, and air stretched over a half billion square kilometers of surface. If the world were the size of an ordinary desktop globe and its surface were viewed edgewise an arm's length away, no trace of the biosphere could be seen with the naked eye. Yet life has divided into millions of species, the fundamental units, each playing a unique role in relation to the whole. Wilson, E.O. 1992. The diversity of life. W.W. Norton and Company, New York. 424 pp. 